\title{
Formation of a Product Promotion Strategy Based on the Analysis of the Behavior of Network Users Through the Bruno de Finetti Paradox
}

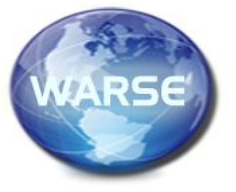

\author{
Volkov D.V. ${ }^{1}$, Zubov M.V. ${ }^{2}$, Shatsky A.A. ${ }^{3}$ \\ ${ }^{1}$ Expert, Russian State Social University, Moscow, Russia, volkovdv@gmail.com \\ ${ }^{2}$ Senior Software Engineer, Integrated systems, Moscow, Russia, zubovmv@gmail.com \\ ${ }^{3}$ Russian State Social University, Moscow, Russia, shatsky@gmail.com
}

\begin{abstract}
The formation of a product promotion strategy in the modern turbulent conditions of the business environment is faced with the multifactorial task of searching for the target audience. Under these conditions, it is important to consider categories such as capital. The paradox of Bruno de Finetti at one time was used to study the ability of insurance companies to conduct business under uncertainty. In modern conditions of a turbulent environment for entrepreneurship, simple farms fall under this category, which makes one think about the inevitability of bankruptcy of enterprises, which was previously proved mathematically. Many different business models are ready to adapt to modern conditions, but not many are ready for such transformations.
\end{abstract}

Key words: strategic inflection point, paradox of the Bruno de Finetti, product promotion model, turbulent environmental, entrepreneurial risk, modern capital.

\section{INTRODUCTION}

To promote a product on the market on the network, you do not need to have any special knowledge - it's extremely simple and accessible to everyone. Enough to have a computer and access to online. There is no need to hire expensive specialists, rent an office, search for a technical base or post ads on the street. You do not even need to have your own advertising agency [25 - 30].

At the same time, the Internet offers far more opportunities for advancement than conventional methods. Here and a huge audience reach, and geographical unlimited, and most importantly - direct access to the buyer and his needs online. Our work is dedicated to the possibilities of promoting services and products in the network. How to immediately attract many customers, how to achieve an avalanche-like growth in coverage answer these questions below.

Forming strategies on the market in the face of uncertainty is a promising area of research. The needs of society are directly dependent on the state of open market relations. Features of the paradox of Bruno De Finetti is to study the possibilities of capital of insurance companies directly in the face of uncertainty. Within the framework of this paradox, the limited capital of an insurance company increases the probability of its ruin in an infinite time to one. The formation of a product promotion strategy, considering the theoretical formulation of the paradox, must rely on the gradual reinvestment of production resources.

The basic concept in online marketing is e-commerce. It implies two main aspects [20]:

1. $\mathrm{B} 2 \mathrm{~B}$ or Business-to-business, that is, direct interaction between entrepreneurs and their exchange of goods, services, franchises.

2. B2C or business interaction with the consumer, that is, bringing goods and services to the final buyer.

The first method involves professional communication of counterparties and a high volume of transactions. In the second case, business marketing is aimed, as a rule, at explaining simple things to the client and motivating him to buy the right product.

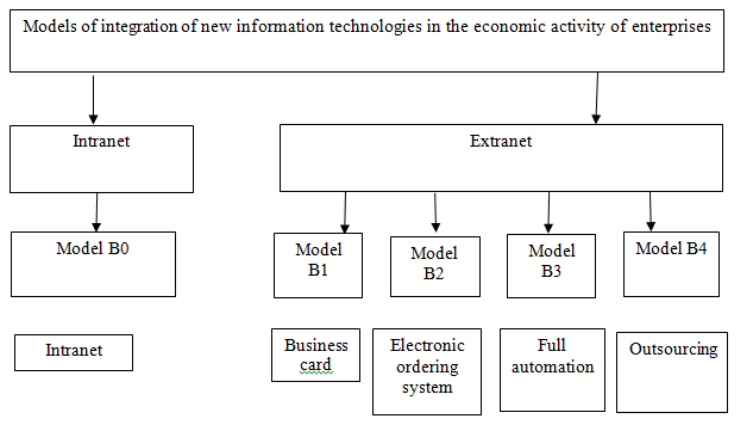

Figure 1: Classification of business models by degree of integration into e-business [4]

There is a universal classification of businesses according to the degree of integration (figure 1) of modern means of communication into economic activity:

- Intranet model (or B0 model). It involves the introduction of an internal network in the enterprise, that is, the ability to organize exchange between employees to improve the efficiency of their work. This method can significantly reduce costs and increase the speed of 
processes. Generally, it increases the literacy of employees and helps them to work more harmoniously in a team, regardless of the location of the workplace. Intranet is a basic step towards business digitalization. Networks are usually isolated from the outside world and have a high level of protection.

- Business card model (model B1). This system, or extranet, is a development of the previous one. Here not only employees, but also clients have access to information resources. This greatly facilitates the process of buying and interacting with the customer. Well-known cash backs, points and discounts are provided by an extranet. Such a network is also protected from the outside world but allows the enterprise to respond flexibly to customer requests - numerous mailings, questionnaires and data collection allow you to create a portrait of a typical user. At the same time, the search for new clients is facilitated and the geography of coverage is expanded, rather than in an offline environment.

- Electronic order model (model B2) shown in figure 2. This is the final stage of development of the two previous ones - its final version. Here all the participants of the business process: the manufacturer, the buyer and the seller are connected in a single information chain. The interaction between them is established directly through the open Internet services and allows you to operate in an inseparable bundle, using both B2B commerce and B2C.

Such a division is based primarily on the consideration of businesses in the advertising key, the key to promoting goods on the market in the face of uncertainty.

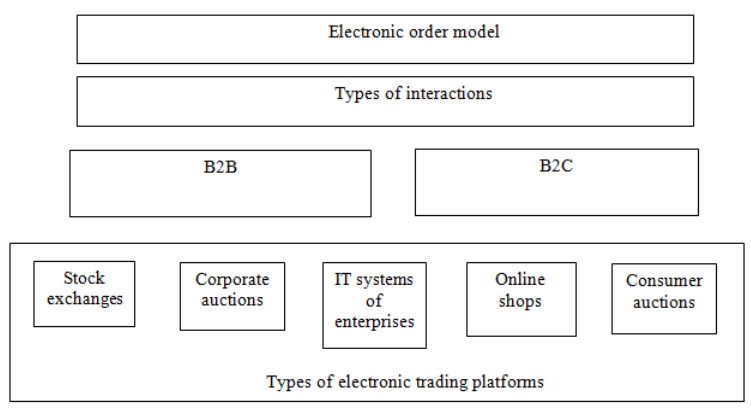

Figure 2: Scheme model of electronic order [15]

The network uses a universal approach to the creation of trading platforms:

1. Specialized platform for the sale and promotion of this type of product or service.

This method is sharpened primarily for regular customers, giving them the opportunity to influence the quality of the product and have remote access to the supplier's warehouses. The client sits in his personal booth on the platform's website and selects by points all the nuances of interest in the order. There are opportunities to control many additional functions of the service - to store archives of purchases, insure transactions or arrange delivery of goods.

2. The second type of commercial platforms are independent electronic trading platforms.
It involves the collection of all buyers and sellers in one place and conducting transactions based on the auction principle. The owner receives income not from the sale of goods and services, but from commissions for transactions and additional related payments, such as entry fees to the platform, guarantees of transactions, etc. It is important to attract large number of customers and organize a convenient environment for interaction.

Key success factors for e-commerce in the B2B sector are [14]:

- a sufficiently large number of participants (reaching a critical mass of clients so that the trade actually goes and the system does not become just a reference);

- accessibility and ease of interaction interfaces;

- a standardized approach to the trade of undercarriage goods: computers, furniture, stationery, tourism and logistics;

- the presence of additional pleasant services: insurance, banking, communication.

In the context of the De Finetti paradox, the person providing the goods / services accordingly evaluates the possibility of entering the market in terms of risks. All this significantly reduces the cost of business. The B2C system is characterized by other success traits:

- availability of online and physical store. For offline enterprises is characterized by the presence of an existing distribution network, suppliers and logistics systems. All this will complement a successful online business;

- it is important to maintain the popularity of a brand or brand at a high level, which requires an increase in such a resource as the reputation, as some authors point out, of a new type of capital $[8,16,23]$;

- active struggle for the client in the conditions of tough competition. Indeed, the success of a business is determined by the final product sold, so it is important to interest the buyer. This requires both a user-friendly interface, and vibrant third-party resources, popular with users, visual sites and affordable prices, high download speeds.

This will help, for example, the creation of alliances between the seller and the Internet provider - commercial services and goods, plus access to the network.

The same reasons can serve as a detrimental factor for business success: poor quality of telecommunications or lack of credit cards among clients, as well as problems with organizing delivery throughout the country, immediately reduce the effectiveness and popularity of the company.

There are two more business models in the classification of the integration of electronic means:

- Model of full automation (model B3). It involves deep user access to all resources and information about the company. Particularly, you can watch the annual reporting, the volume of purchases and sales, information about certificates. Such a system is also called B2B 2C (business-to-business-to-consumer). Its main advantage lies in the fact that despite the openness, it is possible to significantly save on all associated costs. Especially often can be found when using large firms. Indeed, the maintenance of large-scale platforms for finding, 
supporting and retaining customers, selling and delivering goods, requires huge expenses, growing with an explosive nature. The full automation model will allow to switch to robotic servicing of participants, without spending money on real employees. This is how many large firms now work - automakers or retail chains. These criteria in fact transform the concept of capital into a comprehensive category of profitable resources. The implementation of the postulates of the paradox De Finetti finds its way in the accumulation of resources such as information integration and reputation formation in conditions of uncertainty.

- Model of outsourcing (model B4). This is the highest level of Internet business, allowing you to give all related functions to third-party enterprises. The head company remains to determine the overall business strategy and invent something new, follow the market dynamics, etc.

Models of strategy formation in the market for the supply and demand of goods and services consider the focus of business entities. The paradox of Bruno De Finetti was originally used to explain the need for a constant increase in insurance capital. But in the modern conditions of turbulent entrepreneurship, the theoretical meaning of the category of capital is shifting towards information technologies and information, which requires a reappraisal of generally accepted categories and a kind of paradigm transformation under modern realities.

\section{METHODS}

To improve the quality of research, the following list of methodological tools was selected:

1. The method of abstraction - Theoretical-empirical method. In the process of performing analytical and project works, this method allows one to distract from the accidental, situational, from the inessential properties, connections and relations of the phenomenon under study, in our case, the formation of reputation as a specific type of capital.

2. Method of alternatives - This method improves the quality of work performed by objectifying the procedure for choosing a method for solving a specific problem, because when it is used, different alternatives are put forward, options for ways of action, answering a question, solutions for a problem;

3. Method of analysis - Theoretical-empirical method, the dismemberment of a holistic subject into its constituent parts (parties, characteristics, properties or relations) with the aim of their comprehensive consideration.

4. Method of analysis and systematization of data - This method involves the structuring of materials obtained in the course of analytical actions with the subsequent merging of previously disparate concepts and judgments into qualitatively new information.

5. Method of analyzing a circle of subproblems - The method of analyzing a circle of subproblems consists in decomposing the initial problem into interconnected components, taken separately, constituting subproblems (as a rule, considering hierarchical coordination). Then, all possible combinations of components of the problem are compiled, for each of which one or another draft solution is compiled.

6. Problem analysis method - When choosing a subproblem method for research, we could not circumvent the method of basic problems. This method is used to solve problems of choosing alternatives through their multicriteria rating. The method allows to analyze the problem. At the same time, the problem is presented as hierarchically ordered: a) the main goal (main criterion) of rating possible solutions, b) several groups (levels) of onetype factors affecting the rating in one way or another, c) groups of possible solutions, d) links that indicate on the mutual influence of factors and decisions.

\section{LITERATURE REVIEW}

Most of the scientists who work on the problems of forming organizations reputation are scientists practitioners. Among them are: A. Sitnikov, G. Khanov, V. Pakhomov, D. Borodin, D. Gavr, I. Kuzmenkova, A. Shmarov, Yu. Polunin.

Among the well-known foreign experts in the field of the formation of an organization's reputation, one can distinguish K. Fombrun, K. Foss, D. Kartalia, G. Dowling.

The theoretical part of research on the promotion of goods directly in a turbulent environment and in conditions of uncertainty is represented by isolated studies in various fields of scientific knowledge. The complexity of the research question lies in the polyparadigm essence of the phenomenon [9]. So, some researchers consider this phenomenon from the point of view of adherence to a rational choice of communities in which reputation is formed, and some determine the phenomenon as a spontaneous formation with adaptation to conditions in dynamics. That is, according to actual data, we have two main approaches: consumers, and on the other hand, suppliers.

The formation of the opinion of the individual and the public, as a process, in the studies of Russian and foreign scientists is presented in the form of a certain dynamic indicator with a double scale. Reputation, as a result of product promotion, can be both positive and negative [11]. Moreover, the image can be created both by contacting directly with the object, and without it, but using information about the experience of another person [7].

Separate interest worth the works on forecasting the situation in the markets. In particular, the literature covering the conjugating disciplines with the paradox of Bruno De Finetti. Interest in this paradox is reflected in a variety of decision-making strategies in the face of uncertainty in the stock and financial markets $[1,2,5,6]$. The postulates of this theory of the question repeat and adapt the basis of the classical paradox to the realities of financial and stock markets. Given the fact that the volatility of these markets is very high, we can conclude that these technology strategies are applicable when examining the question of supply and demand in the market for goods and services. 
Consider an interesting way to choose the strategy of behavior in the e-commerce system based on the so-called paradox of Bruno de Finetti:

In the seventeenth century, Blaise Pascal introduced the concept of Expected Value. That is, the sum of all the results of activity with weights, considering the positive or negative effect. A hypothesis of optimal behavior was formulated based on the adoption of a strategy of following the maximum expected value. However, in 1738, the Russian mathematician Daniel Bernoulli subjected it to significant criticism, citing the St. Petersburg paradox as an example, about the insurance behavior of a Dutch merchant sending goods to St. Petersburg in winter [21]. He introduced the category Behavior as a function of utility and expected utility instead of expected value. The works of researchers of the twentieth century A. Wald and E. Lehmann advanced this topic, combining previous developments in the framework of a broader Behavioral theory or "decision theory", putting everything on a serious mathematical basis [24].

Modern specialists Frank Ramsay, Bruno de Finetti, Leonard Savage emphasized the subjectivity of probabilities of behavior, which was a new word in assessing possible choices [22]. The work of Maurice Hallet and Daniel Ellsberg showed that the prediction of real human behavior under conditions of risk or uncertainty is not obvious. And the theory of perspectives by Daniel Kaneman and Amos Tversky leans on the economics of behavior on a solid evidence base [17]. The key points of this theory are heightened sensitivities to losses versus gains, and changes in the situation, rather than to its stability.

\section{DISCUSSION}

Until now, talking about the choice of economic strategy, we talked about choosing a company. But in fact, the choice of economic strategy is carried out not by some abstract organization, but by a person (solely or collectively). Therefore, it is important to determine how a person (senior manager) makes decision in the face of uncertainty. The choice of alternative is a kind of top in the decision-making process. Many do not like this stage, try to avoid it or shift it to another, because during this stage the decision maker is forced to take on certain obligations and responsibilities [3].

A good analysis of alternatives allows you to dramatically narrow the scope of choice. When choosing an alternative, 3 approaches can be used: consideration of experience past, conducting an experiment, research and analysis. However, accounting old experience may not always help - experience is past, and the situation is new. Conducting an experiment can be very costly, it will most likely take quite a long time to complete, and after the experiment is over, the time to make decision may be lost. In addition, it is rather difficult to conduct experiments in economics due to the uniqueness of each situation [18, 19].

The most common and possibly the most effective method is research and analysis. It provides a solution to the problem based on the search for relationships between its most possible variables, constraints and fundamentals, which are considered in relation to the goals set. The method also provides for the decomposition of the problem into parts and the study of each of them. An important tool of the method is the development and playback of various models of solutions using quantitative methods and computers [10]. The process of choosing a strategy consists of stages of development, refinement and analysis (evaluation). In practice, these stages are difficult to separate, as they represent different levels of the same analysis process but use different methods.

At the first stage strategies are created - you need to create them as much as possible. On the second, strategies are being developed to the level of adequacy to goals and a general strategy is being formed. In the third, the alternatives are analyzed as part of the overall strategy, the strategy is filled with specific content.

Analysis of the decision-making task under uncertainty conditions requires that the decision maker [12]:

1. compiled a list of available information gathering, experimentation and actions;

2. compiled a list of events that may appear to occur;

3. determined the sequence in which the events are located, the outcomes of which contain the information available to him and the sequential actions that he can take;

4. decided how much he liked the consequences of the various actions available to him;

5. estimated the chances of each specific undefined event.

So, uncertainty has a significant impact on the firm and should be considered when choosing the economic strategy of the company. But the influence of uncertainty at the strategic point of influence (SIP, strategic inflection point) is much greater $[1,2]$. The concept of a strategic impact point (the SI-point abbreviation was introduced in the domestic literature) was introduced by Andrew Grove, CEO of Intel Corporation in his book "Only Paranoids Survive", which immediately became a bestseller in the West [13].

"The things that I tend to be paranoid about are very diverse," Grove writes. "I'm worried about products whose life cycle ends and products put on the market prematurely. I'm worried about factories not working well enough and that I have too many factories. I'm worried about hiring the right people and weakening morals. And, of course, I'm worried about competitors. I'm worried about people figuring out how to do what we do better and cheaper and how to select our customers. But all these worries are pale compared to what I feel about what I call strategic impact points."

The point of strategic impact is the time in the life of any business, when its fundamentals are about to change. This change may mean an opportunity to climb to new heights. But with the same probability it can be a signal of the beginning of the end. The paradox of Bruno de Finetti describes mathematically the hopelessness of any enterprise in these conditions. A strategic impact point may be caused by technological change, but it is more than 
a technological change. The point of strategic impact may be caused by competitors, but it is more than competition. It is a full-scale change in the way business is carried out, so simply adopting a new technology or competing in the same way may not be enough. Inattention to the point of strategic impact can be fatal (Volkov D., 2018). But the point of strategic influence does not always lead to a catastrophe. It creates opportunities for companies willing to act under the new rules.

Thus, the point of strategic impact is a destructive and constructive force at the same time. And it is inevitable. In technology, what can be done will be done. The firm cannot stop the change. The firm can't hide from it. Instead, it should focus on the readiness for these changes. However, no amount of formal planning can predict these changes. But this does not mean that the company should not plan. It should plan how the fire brigade does it: it doesn't know where the next fire will be, but it knows exactly what the fire will be. Accordingly, it distributes own forces in such a way as to react to an unforeseen event as an ordinary event.

\section{CONCLUSION}

Forming a product promotion strategy among network users in a turbulent environment is a rather difficult task with many unknowns. The need of society must be considered in terms of the spontaneous formation of consumer needs.

The point of strategic impact comes when the old strategic picture of the environment dissolves and is replaced by a new one, giving the company the opportunity to rise to the new peak at the conditions of turbulence. However, if an economic entity does not manage its passage through the point of strategic influence, it reaches a peak and after that its business is reduced.

The main task of the company's top management is the timely identification of the point of strategic impact and the selection of a new economic strategy of the company in the face of the uncertainty of what follows this point.

The transformation of the categorical apparatus in the consideration of the theory of the question of capital is necessary for the formation of the actual paradigm of scientific knowledge. In modern conditions, information can act as capital, which forms surplus value. Consequently, information about potential consumers and suppliers also has opportunities for commercialization.

\section{ACKNOWLEDGEMENT}

In the framework of the agreement with the Ministry of education and science of the Russian Federation from 26.09.2017 No. 14.577.21.0251 on the topic: "Development of experimental prototype of a software complex of management of the organization's reputation, built using integrated data sources based on the technology of streaming microsegmentation of the Internet audience, machine learning and data mining».

\section{REFERENCES}

1. Cacioppo,S.High-performance electrophysiological microsegmentation and brain source localization (Book Chapter). Handbook of Psychophysiology, Fourth Edition. 1 January 2016, Pages 101-115. https://doi.org/10.1017/9781107415782.006

2. Cacioppo, S., Weiss, R.M., Cacioppo, J.T. Dynamic spatiotemporal brain analyses of the visual checkerboard task: Similarities and differences between passive and active viewing conditions. Psychophysiology. Volume 53, Issue 10, 1 October 2016, Pages 1496-1506.

https://doi.org/10.1111/psyp.12723

3. Chung, H., Ahn, H.-S., Jasin, S. (Rescaled) MultiAttempt Approximation of Choice Model and Its Application to Assortment Optimization. Production and Operations Management. Volume 28, Issue 2, February 2019, Pages 341-353.

https://doi.org/10.1111/poms.12916

4. Fatas-Villafranca, F., Fernández-Márquez, C.M., Vázquez, F.J. Consumer social learning and industrial dynamics. Economics of Innovation and New Technology. Volume 28, Issue 2, 17 February 2019, Pages 119-141

https://doi.org/10.1080/10438599.2018.1433582

5. Huseynov, S., Kassas, B., Segovia, M.S., Palma, M.A. Incorporating biometric data in models of consumer choice. Applied Economics. Volume 51, Issue 14, 22 March 2019, Pages 1514-1531.

https://doi.org/10.1080/00036846.2018.1527460

6. Joshi, Y., Rahman, Z. Consumers' Sustainable Purchase Behaviour: Modeling the Impact of Psychological Factors. Ecological Economics. Volume 159, May 2019, Pages 235-243.

https://doi.org/10.1016/j.ecolecon.2019.01.025

7. Maloletko, A., Volkov, D., Vishnyakova, V., Shatsky, A. The effect of supply chain and consumer preferences on the formation of economic model. International Journal of Supply Chain Management. Volume 7, Issue 5, October 2018, Pages 684-689.

8. Mämmelä, O., Suomalainen, J., Ahola, K., Ruuska, P., Majanen, M., EUitto, M. Micro-segmenting 5G.IoTBDS 2018 - Proceedings of the 3rd International Conference on Internet of Things, Big Data and Security. 3rd International Conference on Internet of Things, Big Data and Security, IoTBDS 2018; Funchal, Madeira; Portugal; 19 March 2018 до 21 March 2018. Volume 2018-March, 2018, Pages 17-28. https://doi.org/10.5220/0006662700170028

9. McGuire, L., Beattie, G. Talking green and acting green are two different things: An experimental investigation of the relationship between implicit and explicit attitudes and low carbon consumer choice. Semiotica. Volume 2019, Issue 227, 1 March 2019, Pages 99-125.

https://doi.org/10.1515/sem-2017-0138 
10. Novais, L.R., Maqueira, J.M., Bas, Á.O. Current status of research on Customer Segmentation and Supply Chain Flexibility. The Future Challenge of Microsegmentation | [Estado actual de la investigación sobre Segmentación de clientes y Flexibilidad de la cadena de suministro. El desafío futuro de la Microsegmentación]. Direccion y Organizacion. Volume 62, July 2017, Pages 16-34.

11. Oganyan, V.A., Vinogradova, M.V., Volkov, D.V. Internet piracy and vulnerability of digital content. European Research Studies Journal. Volume 21, Issue 4, 2018, Pages 735-743.

12. Sánchez González, P. Halal tourism in Perú: An opportunity for business? | [Turismo halal en Perú: ¿Una oportunidad de negocio?]. Opcion. Volume 33, Issue 82, 2017, Pages 533-549

13. See-To, E.W.K., Ngai, E.W.T. An empirical study of payment technologies, the psychology of consumption, and spending behavior in a retailing context. Information and Management. Volume 56, Issue 3, April 2019, Pages 329-342. https://doi.org/10.1016/j.im.2018.07.007

14. Shangguan, Q., Yuan, H. Design of mobile application interface based on brand image. AHFE 2018 International Conference on Human Factors in Communication of Design, 2018; Orlando; United States; 21 July 2018 do 25 July 2018. Advances in Intelligent Systems and Computing. Volume 796, 2019, Pages 121-130.

https://doi.org/10.1007/978-3-319-93888-2_14

15. Sheu, J.-B., Choi, T.-M. Extended consumer responsibility: Syncretic value-oriented pricing strategies for trade-in-for-upgrade programs. Transportation Research Part E: Logistics and Transportation Review. Volume 122, February 2019, Pages 350-367.

https://doi.org/10.1016/j.tre.2018.12.016

16. Volkov D. V. Analysis of the structure of the modern monetary system. Economy: yesterday, today, tomorrow. 2016. Vol.6. No. 10A. P. 161-170.

17. Volkov D.V., Akhtian A.G., Dgibabov M.R., Semennikova A.I., Kusina O.A. The effective use of human capital through the reduction of working time. International Journal of Environmental and Science Education. 2017. T. 12. № 1. C. 35-46.

18. Volkov, D.V., Maloletko, A.N., Kaurova, O.V. Formation of bounded consumers' rationality based on micro-segmentation. European Research Studies Journal. Volume 21, Issue 4, 2018, Pages 754-762.

19. Volkov, D.V., Vinogradova, M.V., Kulyamina, O.S. The synthesis of modern consumer preferences with the use of social networks in supply chain. International Journal of Supply Chain Management. Volume 7, Issue 5, 2018, Pages 851-857.

20. Mamykin A.A. Internet marketing strategy and tactics // Marketing in Russia and abroad. - 2000. № 2.
21. Ojner O.K., Popov E.V. Virtual marketing and its application in domestic enterprises // Marketing in Russia and abroad. - 2000. - №5.

22. Pimenov Yu.S. Using the Internet in the marketing system// Marketing in Russia and abroad. - 1999. № 1 .

23. Rublevskaya Yu.V., Popov E.V. Business modeling in the Internet environment// Marketing in Russia and abroad. - 2001. - № 2 .

24. Fridland A.Ya. Informatics: processes, systems, resources. M., 2003.

25. Gadzhieva U.B. Socialization of Personality as a Factor in the Mental, Intellectual and SpiritualMoral Development. International Journal of Medicine and Psychology. 2018. Volume 1. Issue 2. Pages 17-20

26. Narkevich L.V., Narkevich E.A. Financial condition analysis in the crisis management system. Russian Economic Bulletin. 2018. Volume 1. Issue 4. Pages $10-24$

27. Tsahaeva A.A., Aminov U.K., Aminova D.K. Driving forces of the development of adaptive behavior of personality: methodological considerations. Modern Scientist. 2017. № 8. Pages 44-47

28. Gadzaov A.F., Dzerzhinskaya M.R. Mathematical methods of analysis of the periodic components of economic processes. Modern Economy Success. 2018. Issue 1. Pages 14-18

29. S.V.R.K.Rao, M.Saritha Devi, A.R.Kishore and Praveen Kumar Wireless sensor Network based Industrial Automation using Internet of Things (IoT). International Journal of Advanced Trends in Computer Science and Engineering. 2018. Volume 7 No. 6 (2018). Pages 82-86 https://doi.org/10.30534/ijatcse/2018/01762018

30. Ramakrishna Rath, R.Tamilkodi, K V Mishra and K Jose Cherian Utilizing Contemporary Benchmark Protocol for Sharing Mobile Ad-hoc Network Environment. International Journal of Advanced Trends in Computer Science and Engineering. 2018. Volume 7 No. 6 (2018). Pages 96-98 https://doi.org/10.30534/ijatcse/2018/04762018 